\title{
Estudo da Adequabilidade da Amostra do Colo do Útero para Exame Citopatológico obtida por Espátula de Ayre e Escova Cervical e por Accellon Combi
}

\author{
Study of Sample Adequacy for Cytopathologic Examination Gathered from the Cervix Uteri by Ayre Spatula plus \\ Cytobrush and Accellon Combi
}

Autora: Denise Schütz Cruzeiro Ferreira

Orientador: Prof.Dr. Nicolau Gregori Czeczko

Dissertação apresentada ao Programa de Pós-graduação em Princípios da Cirurgia da FEMPAR/HUEC/IPEM como requisito parcial para obtenção do grau acadêmico de Mestre, em 10 de dezembro de 2003.

Resumo: O objetivo deste estudo foi avaliar a adequabilidade da amostra para exame citopatológico obtida do óstio do útero e do canal do colo do útero utilizando-se espátula de Ayre associada a escova cervical e Accellon Combi. Este dispositivo consiste de uma haste de plástico com uma extremidade losangular de superfície aveludada, terminando em ponta de 1,8 $\mathrm{cm}$; foi desenvolvido para coletar amostra do óstio do útero e do canal colo do útero simultaneamente. Este estudo, randomizado, transversal e prospectivo, foi realizado através da coleta de amostras no ambulatório de Ginecologia do Hospital Universitário Evangélico de Curitiba no período compreendido entre 2 de abril e 20 de agosto de 2001. Cem mulheres foram distribuídas eqüitativamente em dois grupos. Cada amostra foi colocada em lâmina de vidro única de forma padronizada, submetida à coloração de Papanicolaou e classificada segundo o Sistema Bethesda, sendo a adequabilidade da amostra avaliada pela presença de células metaplásicas e/ou endocervicais. A análise estatística foi feita através do cálculo da probabilidade e Teste do Qui-Quadrado aplicando-se a correção de Yates, adotando-se o índice de significância de 5\%. Uma lâmina de cada grupo foi considerada insatisfatória para ava- liação. A maioria das pacientes do grupo I no menacme apresentou células metaplásicas e/ou endocervicais, havendo diferença significativa em comparação com o grupo II $(p=0,0000025)$. A maioria das pacientes, usuárias ou não de contracepção hormonal do grupo I apresentou células metaplásicas e/ou endocervicais em relação ao grupo II ( $p=0,0069$ e p= 0,000024, respectivamente). A presença de células metaplásicas e/ou endocervicais também foi superior no grupo I em relação ao grupo II, levando em consideração a posição da junção escamo-colunar, quando esta encontrava-se acima ou ao nível do óstio do útero $(\mathrm{p}=0,0438 \mathrm{e} \mathrm{p}=0,00039$, respectivamente). No presente estudo pode-se concluir que a adequabilidade da amostra para exame citopatológico obtida do óstio e do canal do colo do útero coletada por espátula de Ayre + escova cervical foi significativamente superior àquela coletada por Accellon Combi em pacientes no menacme, independente do uso ou não de contracepção hormonal e com junção escamo-colunar acima ou ao nível do óstio do útero.

Palavras-chaves: Amostra, adequabilidade. Espátula de Ayre. Escova Cervical. Accellon Combi. Papanicolaou, esfregaço.

\section{Efeito dos Anti-Retrovirais sobre o Metabolismo dos Glicídios e Lipídios em Gestantes Portadoras}

\section{do HIV-1}

\section{Effect of Antiretroviral Agents on Glucide and Lipid Metabolism in HIV-1 Infected Pregnant Women}

Autora: Patrícia El Beitune

Orientador: Prof. Dr. Geraldo Duarte

Dissertação de Mestrado apresentada ao Curso de Pós-Graduação da Faculdade de Medicina de Ribeirão Preto da Universidade de São Paulo para obtenção do Título de Mestre em Medicina, Área de concentração em Tocoginecologia, em 23 de Julho de 2003.

Objetivos: estudar o efeito das drogas anti-retrovirais sobre o metabolismo glicêmico e lipídico em gestantes portadoras do HIV-1 e a ação dessas medicações sobre o prognóstico fetal e neonatal.

Pacientes e Métodos: estudo prospectivo avaliando 57 gestantes divididas em três grupos. O Grupo AZT foi formado com 20 gestantes portadoras do HIV-1 utili- zando AZT. O Grupo TT, com 25 gestantes portadoras do HIV-1 usando terapia anti-retroviral tríplice (AZT $+3 \mathrm{TC}+\mathrm{NFV}$ ) e o Grupo Controle, composto de 12 gestantes consideradas normais. Foram excluídas gestantes com história pessoal e familiar de diabetes mellitus e dislipidemia. As amostras sangüíneas para dosagens plasmáticas de glicemia de jejum, lipides 
(colesterol total e HDL, triglicerídeos), teste oral de tolerância à glicose com 75 g (TOTG-75 g) foram realizados por ocasião da primeira consulta e repetidas quatro vezes ao longo da gravidez, em intervalos eqüidistantes de tempo. O prognóstico perinatal levou em consideração as taxas de prematuridade, retardo de crescimento intra-útero (RCIU), baixo peso ao nascer, mortalidade perinatal e transmissão vertical do HIV-1. A análise estatística foi realizada utilizando-se testes não paramétricos do qui-quadrado, de Friedman e Kruskal-Wallis.

Resultados: observou-se homogeneidade entre os dados demográficos e antropométricos de realce. Os valores da mediana da área sob a curva derivada das dosagens glicêmicas durante 120 minutos foi de 11.685 $\mathrm{mg} / \mathrm{dl}$ para o Grupo Controle, $13.477 \mathrm{mg} / \mathrm{dl}$ para o Grupo AZT e $13.650 \mathrm{mg} / \mathrm{dl}$ para o Grupo TT ( $p=0,049)$. Esses resultados comprovam associação entre uso de inibidores da protease com o desenvolvimento de intolerância glicêmica durante a gestação. Não se verifi- cou diferença sobre a concentração do colesterol total e da fração HDL decorrente do uso de inibidor da protease, no entanto, causaram aumento significativo da concentração da fração LDL ao longo da gestação em relação ao grupo controle. Observou-se associação significante entre os triglicérides e a carga viral no grupo AZT. Adicionalmente, não se observou nenhum efeito deletério dos anti-retrovirais sobre as taxas de prematuridade, baixo peso ao nascer, RCIU e índices de Apgar. Não houve nenhum caso de transmissão vertical do HIV-1.

Conclusões: verificou-se associação entre uso de inibidores da protease com o desenvolvimento de intolerância glicêmica e elevação significativa da concentração da lipoproteína LDL durante a gestação. Não houve efeitos deletérios sobre o prognóstico gestacional e neonatal imediato.

Palavras-chave: AIDS. Transmissão vertical. Infecção na gravidez. Metabolismo glicídico. Anti-retrovirais.

\title{
VIII Congresso Brasileiro de Ginecologia e Obstetrícia da Infância e Adolescência
}

\section{2 a 25 de setembro de 2004}

\section{Curitiba - PR}

\author{
Informações: \\ EKIPE DE EVENTOS \\ Tel/Fax: (41) 3022-1247
}

E-Mail: ekipe@ekipedeeventos.com.br 